\title{
The ring of fire: Nuances in the surgical management of mitral annular calcification
}

\author{
Demetrios N. Mallios, MD, ${ }^{a}$ Michael E. Bowdish, MD, ${ }^{\mathrm{a}, \mathrm{b}}$ and Vaughn A. Starnes, $\mathrm{MD}^{\mathrm{a}}$
}

From the ${ }^{\mathrm{a} D i v i s i o n}$ of Cardiothoracic Surgery, Department of Surgery, and ${ }^{\mathrm{b}}$ Department of Preventive Medicine, Keck School of Medicine of USC, University of Southern California, Los Angeles, Calif.

Disclosures: Authors have nothing to disclose with regard to commercial support.

Received for publication Sept 18, 2018; accepted for publication Sept 18, 2018; available ahead of print Nov 2, 2018.

Address for reprints: Michael E. Bowdish, MD, Department of Surgery, Keck School of Medicine of USC, University of Southern California, 1520 San Pablo St, Suite 4300, Los Angeles, CA (E-mail: Michael.Bowdish@ med.usc.edu)

J Thorac Cardiovasc Surg 2019;157:570-1

$0022-5223 / \$ 36.00$

Copyright (c) 2018 by The American Association for Thoracic Surgery

https://doi.org/10.1016/j.jtcvs.2018.09.090

Management of mitral annular calcification (MAC) in the operative theater can be quite complex and challenging, even for the most experienced surgeons. Although MAC is not frequently the underlying cause of mitral valve dysfunction, it is often an obstacle the surgeon must face when attempting to repair or replace a pathologic mitral valve. Further, as mentioned by Bedeir and colleagues, ${ }^{1}$ the subpopulation of patients with MAC often experience multiple other comorbid conditions, including atherosclerosis and renal failure. ${ }^{2-4}$ As such, patients with MAC who are undergoing surgical intervention for the mitral valve do not only present a special technical challenge, but they tend to be more medically complex, as well. Modern cardiac surgeons must have intimate knowledge of different strategies for addressing MAC to provide the safest, most effective care possible.

As described by Bedeir and colleagues, ${ }^{1}$ surgeons can broadly approach MAC in 1 of 2 ways: respect or resect. In other words, the bar of annular calcification can be either left alone or debrided, which often requires some type of annular reconstruction thereafter. The obvious concern with the respect strategy is that the annuloplasty ring or valve prosthesis will not seat well, increasing the likelihood of paravalvular leak and possibly compromising the entire repair or replacement. The resect strategy can allow for better placement of a given prosthesis, but it is not without a price. Extensive debridement or enucleation of the calcium bar can predispose to damage of the coronary sinus, conduction tissue, or circumflex coronary artery, with the most dreaded complication being atrioventricular groove disruption and its associated mortality rate of nearly $90 \%$.

To begin, a surgeon must first examine the annulus and the degree of calcification. Is the calcification limited to a few discrete areas on the circumference of the annulus? Is there dense calcification scattered throughout, possibly extending into the ventricular myocardium? Next, a surgeon should assess the likelihood of placing annular sutures in a satisfactory, anatomic arrangement for annuloplasty or

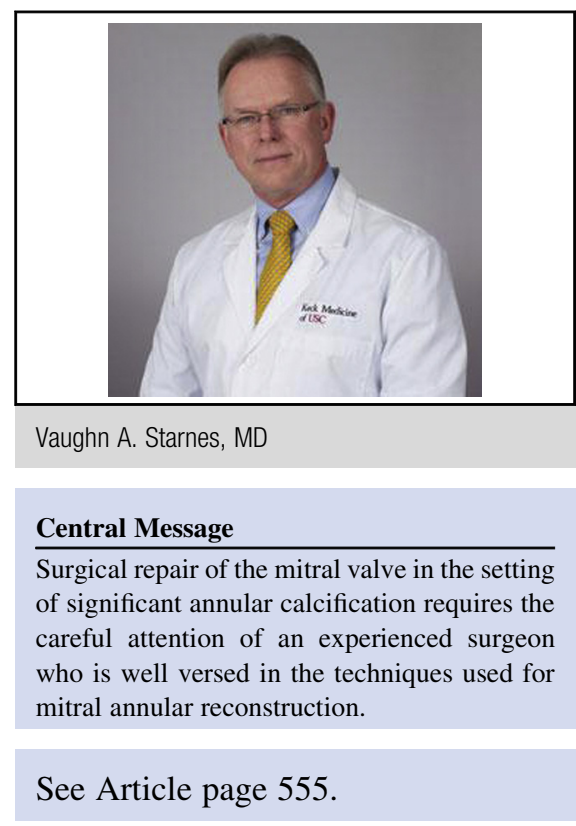

valve replacement with the given calcium burden. In the case of valve replacement, a surgeon must also assess whether or not a prosthesis of adequate size can be placed without debridement of the annular calcium. If either suture placement or the ability to fit an appropriate size prosthesis seems problematic, then debridement of the calcium bar becomes unavoidable. Once careful debridement is complete, it is of paramount importance to thoroughly inspect the integrity of the annulus and quality of remaining tissues. If there exists even the slightest concern for annular disruption, the threshold to place a pericardial patch across the annulus should be low. It has been our experience that prophylactic placement of a broad patch extending from the atrium, across the annulus, and into the ventricle to functionally exclude the area of concern is far simpler than attempting to repair a complete disruption that has been allowed to progress under ventricular pressure. When additional annular reconstruction is necessary, our preference is the David technique. ${ }^{6}$ Alternatively, in patients where only limited debridement of annular calcium is needed and there is low suspicion for annular disruption, placement of a felt strip on the ventricle side of the annulus to serve as a buttress for the annular sutures will suffice.

The goal when addressing MAC in the operating room should be 2-fold: minimize the risk of complications while maximizing the quality of the surgical repair or replacement of the mitral valve. To achieve a good result, we advocate 
for a methodical approach. In brief, all patients with MAC who are undergoing surgical intervention on a mitral valve, with or without concomitant procedure, should undergo extensive preoperative workup and imaging. The particular risks inherent to their underlying anatomy should be discussed. In the operating room, time should be taken to carefully assess the mitral valve itself, as well as the annulus. If the decision is made to work around the annulus and avoid debridement, suture placement should be done fastidiously with the aim to seat the prosthesis cleanly. When annular debridement is necessary, a surgeon should be adroit in the use of both the Carpentier and David methods of annular reconstruction, with a low threshold for additional patching if annular disruption is suspected. ${ }^{6,7}$ Looking forward, particularly difficult patients with severe MAC may ultimately benefit from transcatheter techniques, although further studies are necessary.

\section{References}

1. Bedeir K, Kaneko T, Aranki S. Current and evolving strategies in the management of severe mitral annular calcification. J Thorac Cardiovasc Surg. 2019;157:555-66.

2. Fox CS, Vasan RS, Parise H, Levy D, O’Donnell CJ, D'Agostino RB, et al. Mitral annular calcification predicts cardiovascular morbidity and mortality: the Framingham Heart Study. Circulation. 2003;107:1492-6.

3. Adler Y, Fink N, Spector D, Wiser I, Sagie A. Mitral annulus calcification-a window to diffuse atherosclerosis of the vascular system. Atherosclerosis. 2001;155:1-8.

4. Asselbergs FW, Mozaffarian D, Katz R, Kestenbaum B, Fried LF, Gottdiener JS, et al. Association of renal function with cardiac calcifications in older adults: the cardiovascular health study. Nephrol Dial Transplant. 2009;24:834-40.

5. Deniz H, Sokullu O, Sanioglu S, Sargin M, Ozay B, Ayoglu U, et al. Risk factors for posterior ventricular rupture after mitral valve replacement: results of $2560 \mathrm{pa}-$ tients. Eur J Cardiothorac Surg. 2008;34:780-4.

6. David TE, Feindel CM, Armstrong S, Sun Z. Reconstruction of the mitral annulus. A 10-year experience. J Thorac Cardiovasc Surg. 1995;110:1323-32.

7. Carpentier AF, Pellerin M, Fuzellier JF, Relland JY. Extensive calcification of the mitral valve annulus; pathology and surgical management. J Thorac Cardiovasc Surg. 1996;111:718-29. 